\title{
New criteria for selecting reliable Thellier-type paleointensity results from the 1960 Kilauea lava flows, Hawaii
}

\author{
Doohee Jeong ${ }^{1}$, Qingsong Liu ${ }^{1,2^{*}}$, Yuhji Yamamoto ${ }^{3}$, Yongjae Yu ${ }^{4}$, Xiang Zhao ${ }^{5}$ and Huafeng Qin ${ }^{6}$
}

\begin{abstract}
Thellier-type paleointensity experiments associated with partial thermal remanent magnetization checks have been widely used to determine paleointensity values from volcanic and archaeological media. However, previous studies have revealed that a substantial portion of paleointensity results with positive checks for historical lava samples largely fails to predict known Earth magnetic field intensity values. To determine the fidelity of paleointensity values, conventional Thellier-type paleointensity experiments were performed on Kilauea lava flows that erupted in 1960. The positive partial thermal remanent magnetization checks for our results range from $30.28 \pm 1.38 \mu \mathrm{T}$ to $52.94 \pm 1.89 \mu \mathrm{T}$. This strongly indicates that conventional paleointensity checks cannot guarantee the fidelity of paleointensity results, especially when the unblocking temperatures for the newly formed magnetic particles are higher than the treatment temperature. Therefore, in this study, to check for thermal alteration during heating, the temperature dependence of the hysteresis parameter measured at room temperature for the thermally treated samples was also measured. Our new results show that nearly all biased paleointensity values correspond to a ratio of the coercivity of remanence to the magnetic coercivity of $>3$ and a chemical alteration index $>\sim 10 \%$, which indicates the strong effect of the domain state and thermal alteration on the fidelity of the paleointensity results. Our study provides feasible criteria to further improve the fidelity of paleointensity estimations.
\end{abstract}

Keywords: Thellier-type experiment, Paleointensity, Domain state, Thermal alteration

\section{Introduction}

Variations in the Earth's magnetic field intensity at different time scales contain significant information concerning the growth of the Earth's deep interior (Macouin et al. 2004; Tarduno et al. 2007; Biggin et al. 2015) and the evolution of the geodynamo (Larson and Olson 1991; Olson et al. 2013). There are two different types of approaches used to trace temporal variations in the geomagnetic field intensity: relative paleointensity (RPI) determinations (Tauxe 1993) and absolute paleointensity determinations (Thellier 1938; Thellier and Thellier 1959). Sediments

\footnotetext{
*Correspondence: qsliu@sustech.edu.cn

${ }^{1}$ Centre for Marine Magnetism (CM2), Department of Ocean Science and Engineering, Southern University of Science and Technology, Shenzhen 518055, China

Full list of author information is available at the end of the article
}

carry depositional or post-depositional remanent magnetization, and are excellent media to record the semicontinuous RPI (Valet et al. 2005; Yamazaki and Oda 2005; Channell et al. 2009; Ziegler et al. 2011). Meanwhile, volcanic rocks are suitable for high-accuracy spot readings of the ancient geomagnetic field intensity.

Modern absolute paleointensity determinations require multiple step heating with systematic alteration (or consistency) checks. The Thellier protocol (Thellier 1938) was initially proposed to compare the destruction of thermoremanent magnetization (TRM) and the acquisition of laboratory-induced partial thermoremanent magnetization (pTRM) at equal temperatures. Thellier-type double-heating techniques include multiple slight modifications, with each method having advantages and disadvantages (Thellier and Thellier 1959; Coe 1967; Aitken 
et al. 1988; Yu et al. 2004). The most commonly used technique is the so-called "Coe" protocol (Coe 1967) in which the specimen is first heated to an initial temperature $\left(T_{\mathrm{i}}\right)$ in a zero-field to determine the natural remanent magnetization (NRM) lost. To determine the pTRM gained, the specimen is reheated to $T_{\mathrm{i}}$ under an in-field condition. Aitken et al. (1988) modified the Coe method (1967) by reversing the order of the double heating. The IZZI protocol alternates the Aitken method and the Coe method at every other step (Yu et al. 2004). Detailed reviews of various Thellier-type techniques have been provided by Valet (2003) and Biggin (2010).

Once a paleointensity determination is performed, the results are displayed on an Arai plot (Nagata et al. 1963) where the absolute value of the slope of the NRM remaining versus the pTRM gained indicates the ratio of the ancient to laboratory magnetic field intensities. Only stable single-domain (SD) particles follow linear Arai plots, reflecting identical spectra of the unblocking temperature $\left(T_{\mathrm{ub}}\right)$ and the blocking temperature $\left(T_{\mathrm{b}}\right)$. Multi-domain (MD) and pseudo-single-domain (PSD) grains tend to produce non-linear Arai plots (Dunlop and Özdemir 2001; Paterson et al. 2015). Inequivalent $T_{\text {ub }}$ over $T_{\mathrm{b}}$ values are responsible for such non-linearities in Arai plots. The pTRM tail check was introduced to duplicate the previsouly acquired pTRM for non-uniformly magnetized TRM (Riisager et al. 2000; Riisager and Riisager 2001; Yu and Dunlop 2003). In addition to the physical origin, chemical contributions can alter the linearity of an Arai plot. For example, the growth of newly formed magnetic particles via chemical transformations (Yamamoto et al. 2003) can induce thermochemical remanent magnetization (TCRM).

The most convenient and easiest method to ensure high-fidelity paleointensity determinations is to check the quality of the paleointensity determination using historic rocks whose geomagnetic field intensities are readily known (e.g., using the International Geomagnetic Reference Field (IGRF), Thébault et al. 2015). Accordingly, the reliabilities of absolute paleointensity determinations have been tested using historic lava samples from Hawaii in the US (Tsunakawa and Shaw 1994; Chauvin et al. 2005; Oishi et al. 2005; Herrero-Bervera and Valet 2009; Morales et al. 2010; Cromwell et al. 2015), Italy (Calvo et al. 2002), Japan (Tsunakawa and Shaw 1994; Yu 2012), Spain (de Groot et al. 2015; Calvo et al. 2016), and the western US (Coe et al. 2004).

Of these various historic sites, the 1960 historic lava flows in Hawaii have drawn considerable attention because of their accessibility (Abokodair 1977; Tanaka and Kono, 1991; Tsunakawa and Shaw 1994; Tanaka et al. 1995; Valet and Herrero-Bervera 2000; Hill and Shaw 2000; Yamamoto et al. 2003; Chauvin et al. 2005;
Hettero-Bervera and Valet 2009). However, relatively easier accessibility does not guarantee a successful duplication of the geomagnetic field intensity information. Böhnel et al. (2011) systematically summarized these paleointensity estimations and concluded that the paleointensity estimations depend on several factors including the lava cooling rate, the temperature treatment intervals, and experimental methods. In fact, the 1960 Hawaiian lava samples have often yielded paleointensity determinations biased toward higher/lower values by up to $10-20 \%$ or even more (Tanaka and Kono 1991; Tsunakawa and Shaw 1994; Tanaka et al. 1995; Valet and Herrero-Bervera 2000; Hill and Shaw 2000; Yamamoto et al. 2003; Herrero-Bervera and Valet 2009; Morales et al. 2010; Cromwell et al. 2015). For example, Tanaka and Kono (1991) investigated the 1960 lava flows on the Big Island of Hawaii and obtained a paleointensity that was approximately $50 \%$ higher than the expected value. Conversely, a recent microwave study using the IZZI+ protocol produced paleointensity estimates consistent with the expected values (Grappone et al. 2019) and proposed that undetected chemical alterations are significant factors influencing the low paleointensity values found using conventional Thellier-type methods. The origin of heterogeneous or anomalous paleointensity outcomes likely lies in the influence of TCRM (Yamamoto et al. 2003), the presence of local magnetic anomalies (Morales et al. 2010), and/or the alteration and neo-formation of magnetic particles during repeated heating (Zhao et al. 2014). In addition to chemical alteration effects during paleointensity experiments, Fabian (2009) proposed that partial dissolution or low-temperature oxidization after TRM acquisition could seriously contaminate the original TRM but could not be distinguished from the true TRM in Thellier experiments. In addition, Cromwell et al. (2015) collected individual volcanic glass samples from the 1960 Hawaiian lava flows; these samples yielded nearly ideal estimation of the expected paleointensity, and had a much lower variance than published data from the same volcanic unit. This strongly indicates that domain effects should also be considered in paleointensity estimations.

The present study was designed to combine the domain state and the temperature dependence of magnetic hysteresis as a potential alteration check. We aim to determine the exact mechanisms for biased paleointensity results using positive pTRM checks. This is extremely important for paleointensity determinations of older rocks.

\section{Samples}

The Big Island of Hawaii, located on the Hawaiian hotspot, is currently volcanically active. The highest volcano on the island, Mauna Kea, is located to the 


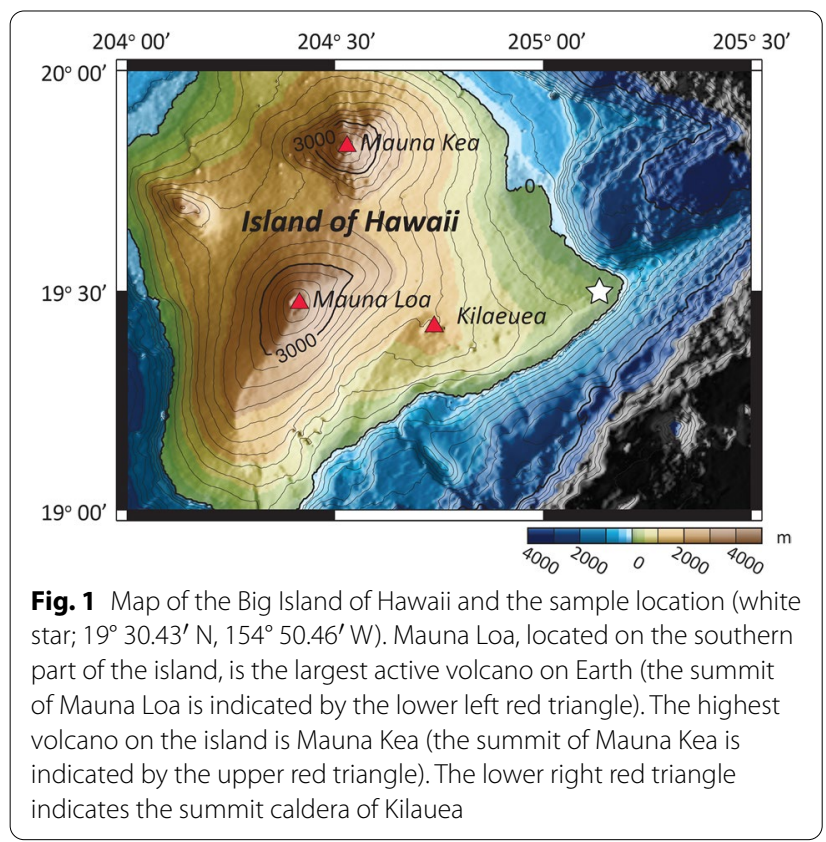

north-west of the sampling site. Mauna Kea erupted from 300,000 to $\sim 4000$ years ago (Frey et al. 1990) (Fig. 1, upper red triangle). Mauna Loa is one of the largest volcanoes on the Big Island of Hawaii and is an active volcano, along with Kilauea. Kilauea is located at $19^{\circ} 3^{\prime} \mathrm{N}, 204^{\circ} 3^{\prime} \mathrm{E}$ (Fig. 1). On January 13, 1960, an eruption began along the east rift zone of Kilauea. The 1960 eruption lasted for approximately a month, and the lava covered an area of $10 \mathrm{~km}^{2}$ (Ritcher et al. 1970; Rowland and Walker 1987). According to the IGRF model, the geomagnetic field intensity at the eruption site should have been $36.2 \mu \mathrm{T}$. Paleointensity determinations have yielded results ranging from $33.55 \mu \mathrm{T}$ to $53.5 \mu \mathrm{T}$ (Tanaka and Kono 1991; Tsunakawa and Shaw 1994; Tanaka et al. 1995; and Yamamoto et al. 2003). For example, Tanaka and Kono (1991) documented the presence of two segments in an Arai plot. They picked lower temperature segment because the PTRM checks failed at higher temperature ranges. As a consequence, their paleointensity determinations were overestimated (Tanaka and Kono 1991).

A total of 30 cylindrically shaped basaltic core samples were collected from the historic Kilauea flows using a portable engine drill in March 1998 (Yamamoto et al. 2003). The sampling site was a roadcut of exposed lava $\sim 4 \mathrm{~m}$ thick and $\sim 15 \mathrm{~m}$ wide. On the basis of the core positions, the samples were divided into four subsites, designated A1-A5, B1-B7, B8-B10, and C1-C4 (Yamamoto et al. 2003). The rock magnetic results (Yamamoto et al. 2003) indicate that the dominant magnetic carrier is the PSD low-titanium magnetite.

\section{Experiments and results} New rock magnetic measurements

Magnetic hysteresis measurements were performed using a variable field translation balance with a saturation field of $1 \mathrm{~T}$. Values of the saturation magnetization $\left(M_{\mathrm{s}}\right)$, saturation remanence $\left(M_{\mathrm{rs}}\right)$, and magnetic coercivity $\left(B_{\mathrm{c}}\right)$ were calculated after removing the paramagnetic portion. The coercivity of remanence $\left(B_{\mathrm{cr}}\right)$ was determined using stepwise backfield demagnetization measurements. At least one chip was used for each of the 30 different basaltic cores. The magnetic hysteresis results are displayed on a Day diagram (Day et al. 1977) according to the criteria of Dunlop (2002) (Fig. 2a). All the samples fall within the pseudo-single-domain (PSD) range (Fig. 2a). The squareness versus coercivity plot shows a linear correlation with a mean slope value of approximately $0.01 \mathrm{mT}^{-1}$ (Fig. 2b).

The first-order reversal curve (FORC) diagrams were also obtained (Smooth factor $=8$ ), using an alternating gradient force magnetometer (MicroMag 2900). The results from a chip of the A1 sample display closing and elongated contours, reflecting the fine-grained nature of the sample (Fig. 3), as well as additional PSD features (Fig. 3).

\section{Temperature-dependent rock magnetic properties}

The paleointensity results can vary considerably as a result of several factors. Non-linear features in Arai plots can be caused either by MD effects or by thermal alteration during heating. To determine the exact reason for the non-linearity, sister samples were heated to the same paleointensity measurement heating steps $(200,300,350$, $400,450,480,500,520,540,560,580$, and $\left.600{ }^{\circ} \mathrm{C}\right)$. Then, after heating, their hysteresis loops were measured at
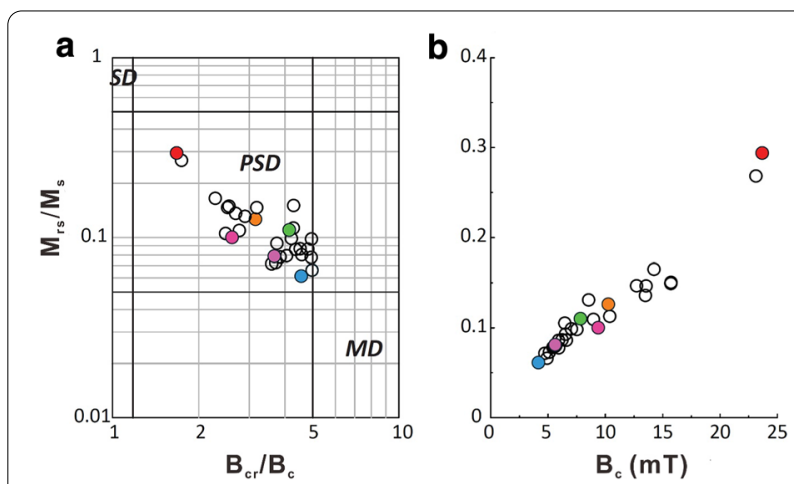

Fig. 2 Hysteresis parameters displayed in a a Day plot, and $\mathbf{b}$ a function of coercivity and remanence ratio. SD: single domain, PSD: pseudo-single domain, MD: multi-domain. The colors correspond to the samples shown in Fig. 3: red indicates sample A1 (Fig. 3a); orange indicates sample B4 (Fig. 3b), magenta indicates sample B8 (Fig. 3C), green indicates sample C7 (Fig. 3d), blue indicates sample A11 (Fig. 3e), and purple indicates sample C2 (Fig. 3f) 

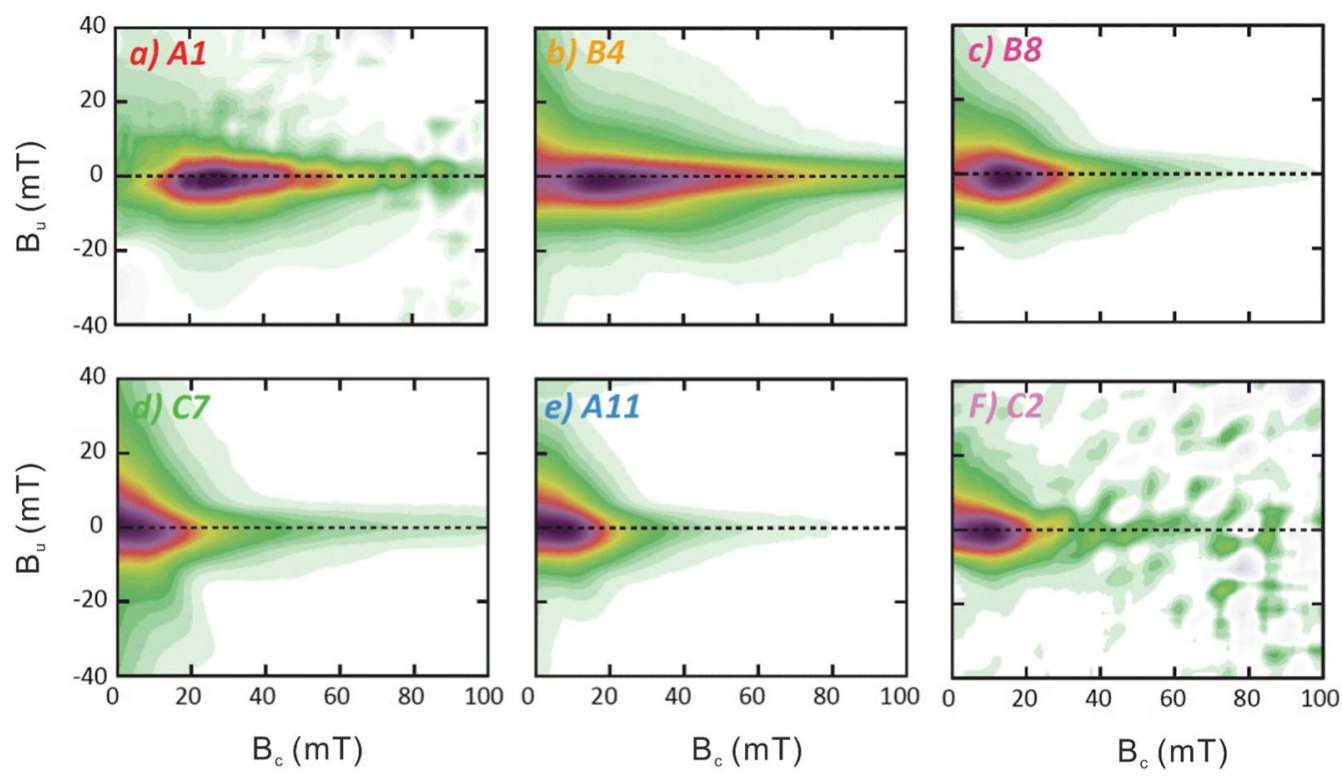

Fig. 3 First-order reversal curve (FORC) diagrams for representative samples (smoothing factor $=8$ )

room temperature for each step for each step to detect thermal effects (Haag et al. 1995; Henry et al. 2005; Smirnov and Tarduno 2003; Qin et al. 2011). The room temperature-normalized magnetic saturation remanence $\left(\mathrm{Mrs}_{\text {room }}\right)$ versus temperature is shown in Fig. 4. The $\mathrm{M}_{\mathrm{rs}}$ ${ }_{\mathrm{T}} / \mathrm{M}_{\mathrm{rs} \text { room }}$ features can be divided into two groups from room temperature to $500{ }^{\circ} \mathrm{C}$. The first group is relatively stable from 300 to $500{ }^{\circ} \mathrm{C}$ (Fig. $4 \mathrm{a}, \mathrm{e}, \mathrm{f}$ and g). The second group exhibits a dome-like feature (Fig. $4 \mathrm{~b}-\mathrm{d}, \mathrm{h}$ and i). For nature samples, the influences of the viscous remanent magnetization (VRM) usually reach $300{ }^{\circ} \mathrm{C}$. Thus, to provide a more practical model, a new interval from 300 to $500{ }^{\circ} \mathrm{C}$ was chosen to recalculate the paleointensity (this is referred to as the restricted paleointensity) (Table 1).

\section{Paleointensity determination}

Paleointensity determinations were performed using the IZZI protocol. Stepwise double heating was performed in 12 steps at 200, 300, 350, 400, 450, 480, 500, 520, 540, 560,580 , and $600{ }^{\circ} \mathrm{C}$. We performed pTRM checks at 300 , $400,480,520$, and $560^{\circ} \mathrm{C}$. A laboratory field of $20 \mu \mathrm{T}$ was used for all of the in-field step heating determinations.

Paleointensity determinations were accepted when they passed the following selection criteria: (1) the demagnetization of NRM must be univectorial with the anchored maximum angular deviation (MAD) angles of $<4^{\circ}$ (Kirschvink 1980); (2) all pTRM\% checks must be within 5\% (Paterson et al. 2014); (3) the angle between the principal fractions anchored to and free from the origin DANG (Tauxe and Staudigel 2004) should be $<4^{\circ}$; (4) at least six data points with more than $48 \%$ of the extrapolated NRM fraction (Coe et al. 1978) must be included in the regression analysis; and (5) the degree of scatter around the best-fit line normalized by the estimated slope (York 1969) should be $<5 \%$. According to these selection criteria, a total of six samples had successful paleointensity estimations (Fig. 5; Table 1). The magnetization was removed at $560{ }^{\circ} \mathrm{C}(<10 \%)$ with a few exceptions. The paleointensity results range from $30.28 \pm 1.38$ $\mu \mathrm{T}$ to $52.94 \pm 1.89 \mu \mathrm{T}$. Several samples yielded biased values significantly higher than the expected values (IGRF model $\approx 36.1 \mu \mathrm{T})$. Such erroneous results with high estimated paleointensity have been attributed to the production of thermochemical chemical remanent magnetization (TCRM) during the heating processes (Yamamoto et al. 2003). A total of 6 out of 30 samples passed the stringent selection criteria (Table 1). The mean paleointensity of $43.40 \pm 8.31 \mu \mathrm{T}$ from 6 accepted samples disagrees with the predicted value $(36.2 \mu \mathrm{T})$ by $19.9 \%$.

For all six accepted samples, the temperature dependence of $M_{\mathrm{rs}}$ indicates that the $M_{\mathrm{rs}}$ values remain relatively stable from 300 to $500{ }^{\circ} \mathrm{C}$ (Fig. 4) and change significantly at higher temperature. Accordingly, we recalculated the paleointensity estimates using only the data points acquired from 300 to $500{ }^{\circ} \mathrm{C}$ (Table 1). Four samples yielded essentially identical intensity estimates within the uncertainty with or without the re-calculation (Fig. 6, Table 1). However, the paleointensity estimates from four samples (A1, B2, B5, and B7) were significantly lowered after the re-calculation using the $300-500{ }^{\circ} \mathrm{C}$ steps (Fig. 6, Table 1), which is more consistent with the 

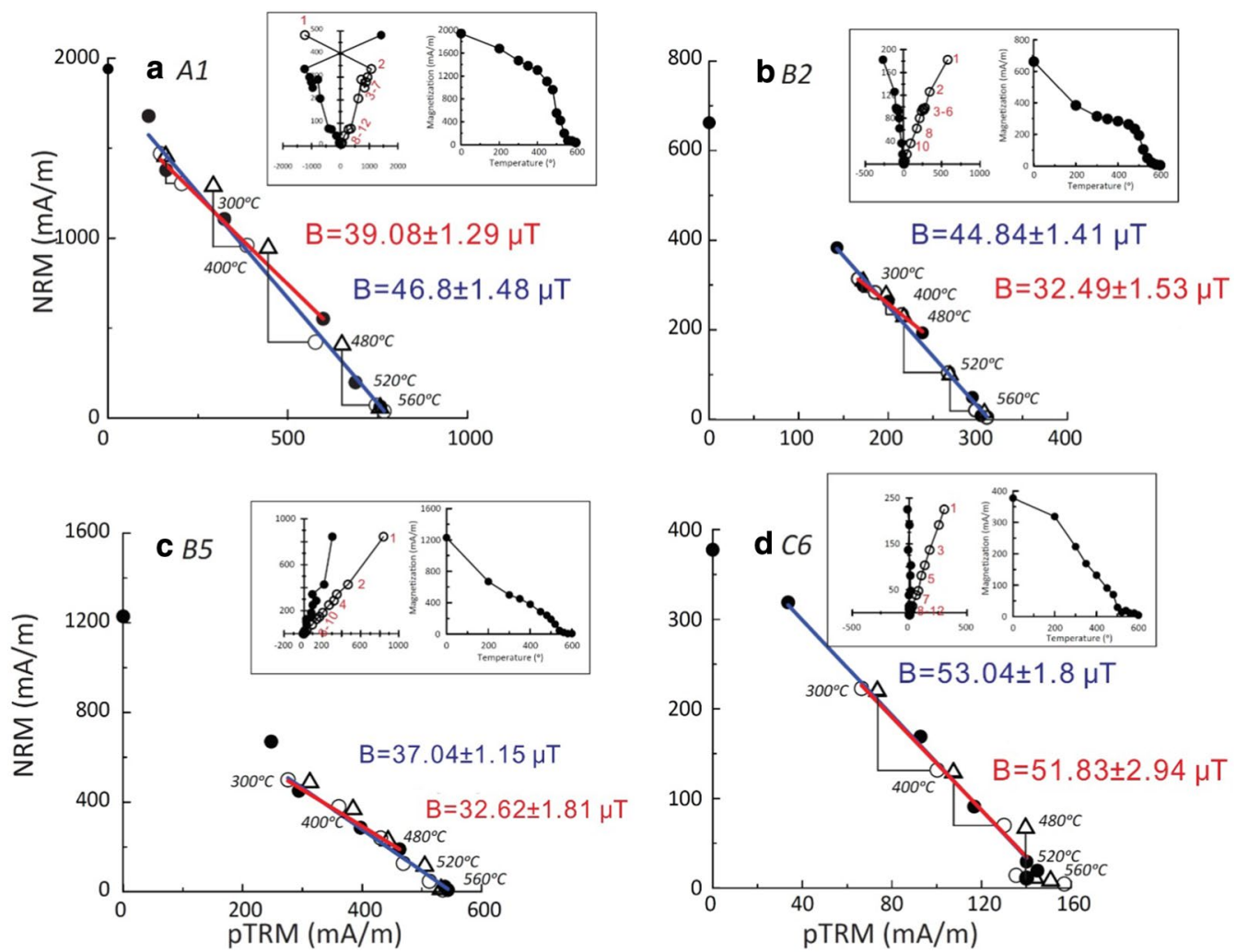

Fig. 4 Arai plot illustrating successful paleointensity determinations using the IZZI protocol (in-zero and zero-in field steps are indicated by the solid and open circles, respectively). pTRM checks (triangles) reproduce the origin pTRM within 5\%. The insets are shown orthogonal vector plots, with solid symbols corresponding to horizontal planes and open symbols corresponding to vertical planes, extracted from the zero-field steps and representative thermal demagnetization patterns

Table 1 Paleointensity results from the 1960 Hawaiian lava flows erupted from Kilauea

\begin{tabular}{|c|c|c|c|c|c|c|c|c|}
\hline Sample & $\Delta \mathrm{T}\left({ }^{\circ} \mathrm{C}\right)$ & $n$ & $f$ & $g$ & $q$ & $\beta$ & $B(\mu \mathrm{T})$ & $B g(\mu \mathrm{T})$ \\
\hline \multicolumn{9}{|c|}{ Conventional paleointensity } \\
\hline $\mathrm{A} 1^{*}$ & $200-600$ & 12 & 0.89 & 0.84 & 23.24 & 3.25 & $46.97 \pm 2.42$ & \\
\hline A15 & $200-540$ & 9 & 0.74 & 0.75 & 15.13 & 3.66 & $48.66 \pm 1.78$ & \\
\hline $\mathrm{B} 2^{*}$ & $300-600$ & 11 & 0.68 & 0.66 & 11.78 & 3.78 & $44.50 \pm 1.68$ & \\
\hline$B 5^{*}$ & $300-580$ & 10 & 0.48 & 0.75 & 8.87 & 4.06 & $37.05 \pm 1.50$ & \\
\hline$B 7^{*}$ & $300-540$ & 8 & 0.63 & 0.69 & 5.65 & 4.56 & $30.28 \pm 1.38$ & \\
\hline $\mathrm{C} 6$ & $200-500$ & 7 & 0.72 & 0.75 & 15.09 & 3.57 & $52.94 \pm 1.89$ & \\
\hline Mean & & 7 & & & & & $43.40 \pm 8.31$ & \\
\hline Mean* & & 4 & & & & & $39.70 \pm 7.56$ & \\
\hline \multicolumn{9}{|c|}{ Restricted paleointensity } \\
\hline $\mathrm{A} 1^{*}$ & $300-500$ & 6 & 0.53 & 0.66 & 10.86 & 3.25 & $39.18 \pm 2.04$ & 7.79 \\
\hline $\mathrm{B} 2^{*}$ & & & 0.49 & 0.63 & 6.64 & 4.62 & $32.20 \pm 1.49$ & 12.30 \\
\hline $\mathrm{B}^{*}$ & & & 0.33 & 0.48 & 2.8 & 5.55 & $32.67 \pm 1.81$ & 4.38 \\
\hline $\mathrm{B}^{*}$ & & & 0.25 & 0.67 & 1.83 & 9.14 & $30.75 \pm 2.81$ & 0.47 \\
\hline Mean & & 4 & & & & & $33.70 \pm 3.74$ & \\
\hline Mean* & & 2 & & & & & $35.69 \pm 4.94$ & \\
\hline
\end{tabular}

$\Delta T$ is the temperature interval used in paleointensity estimation; $n$ is the number of points used in paleointensity estimation; $f, g, q, \beta$ and $\theta$ are NRM fraction, gap factor, quality factor, and the standard error of the slope and different angle of the selected NRM component from the origin on the orthogonal plot; $B g(\mu T)$ indicates the differences in the paleointensity estimations between the conventional IZZI approach and the more restricted values using the temperature interval from 300 to $500{ }^{\circ} \mathrm{C}$; and ${ }^{*}$ indicates that the value meets the condition $\left(B_{\mathrm{c} r} / B_{c}<3\right.$ and $\left.\mathrm{Cl}<10 \%\right)$ 


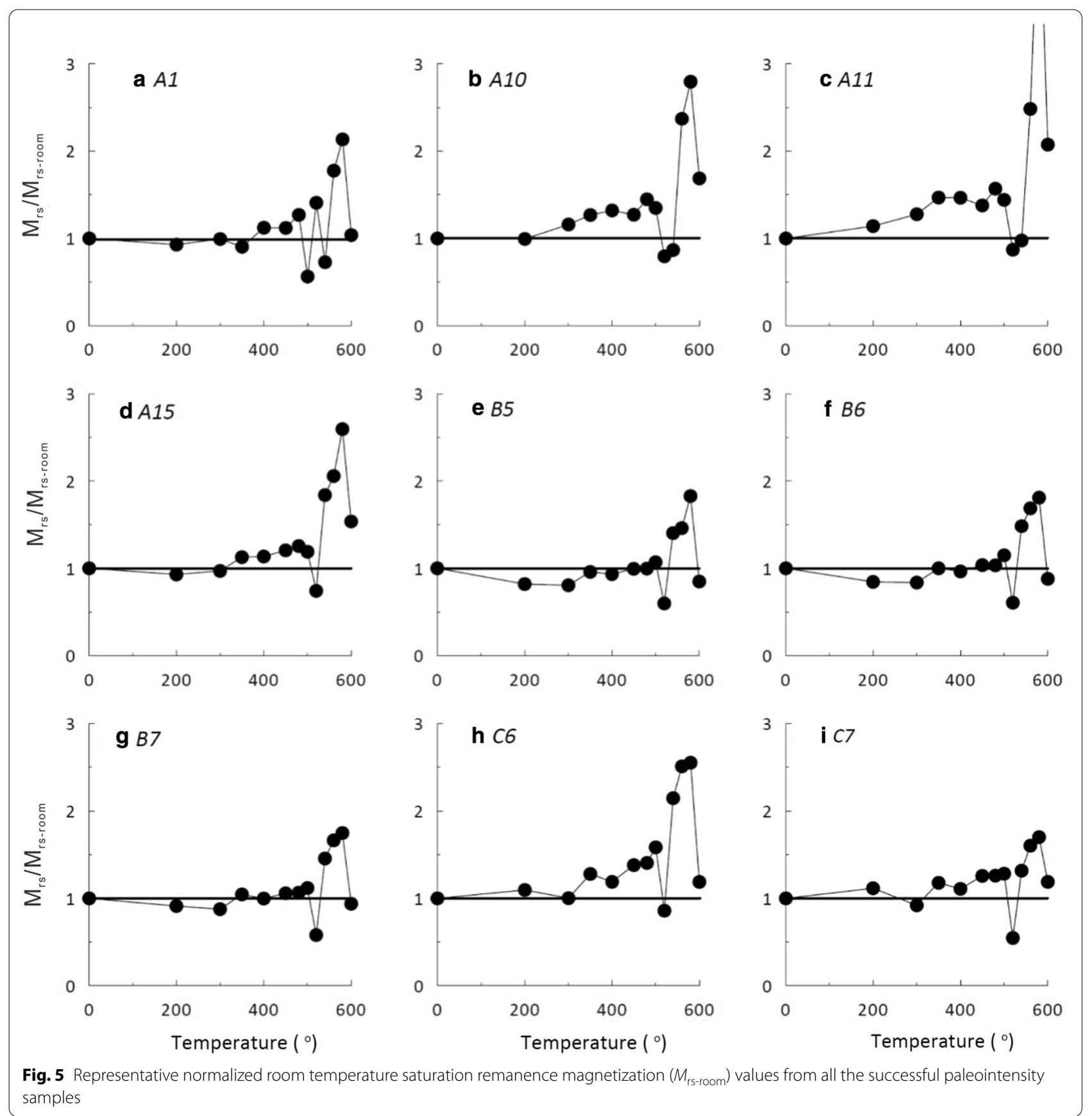

expected value although the experimental success rate is highly reduced.

\section{Discussion}

The studied lava flows erupted in 1960 from Kilauea on the Big Island of Hawaii. Altogether, 6 out of 30 samples yielded paleointensity results with positive pTRM checks using the IZZI protocol. The mean value of the paleointensity was $\sim 43.4 \mu \mathrm{T}$, which is higher than the expected value for the study area $(\sim 36.1 \mu \mathrm{T})$. In addition, the paleointensity results range widely between $30.288 \pm 1.38$ and $52.94 \pm 1.89 \mu \mathrm{T}$ (Fig. 6).

Previous studies have already shown that positive pTRM checks do not guarantee the fidelity of paleointensity results for Thellier-type experiments because the unblocking temperatures of the newly formed magnetic particles could be higher than the treatment temperature (Coe 1967; Coe et al. 1978; Wang and Kent 


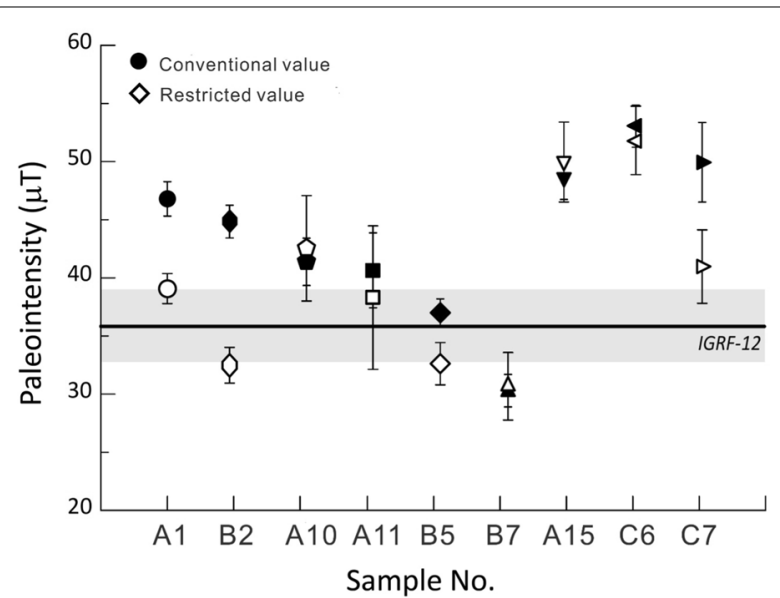

Fig. 6 Comparison of traditional selection values and restricted selection values from each sample. The horizontal line indicates the IGRF-12 value at the sampling site $(36.1 \mu \mathrm{T})$ and the grey region represents the $10 \%$ error range)

2013, 2021; Zhao et al. 2014). However, such a flaw can be overcome by examining the room temperature dependence of the magnetic parameters (Smirnov and Tarduno 2003; Qin et al. 2011). Upon thermal treatment, two types of mineral transformations occur. The first type of alteration can produce newly formed strongly magnetic minerals. Despite the distribution of the unblocking temperature, the enhanced concentration dependence of the magnetic parameters can sensitively detect the neo-formation of magnetic minerals.

The second type of thermal alteration does not produce new minerals, but can oxidize the primary magnetic minerals into a less magnetic state, e.g., from magnetite to maghemite, which could significantly decrease the saturation magnetization (also ARM and SIRM values). The first and second types of thermal alterations decrease and enhance the estimated paleointensity values, respectively (Zhao et al. 2014). Accordingly, Qin et al. (2011) adopted a new parameter called the chemical alteration index $(\mathrm{CI})$, which can be defined, for example, by $M_{\text {rs } \_t^{\circ}{ }^{\circ}} / M_{\text {rs_raw }}$, where $M_{\text {rs_t }}{ }^{\circ} \mathrm{C}$ and $M_{\mathrm{rs} \_ \text {raw }}$ indicate the $M_{\mathrm{s}}$ values for the samples after the $t^{\circ} \mathrm{C}$ thermal treatment and the raw sample, respectively. The selection of the treatment temperature, $t^{\circ} \mathrm{C}$, should be determined according to the exact experiment results. For example, in this study, we selected $300{ }^{\circ} \mathrm{C}$ and $500{ }^{\circ} \mathrm{C}$ for $\mathrm{CI}$ to track the possible chemical changes and this temperature selection is more practical for natural samples. In addition to the conventional pTRM checks, CI values should be less than a threshold value (e.g., $<10 \%)$, to indicate weakly thermal alteration effects. Such a rationale has been applied in this study.

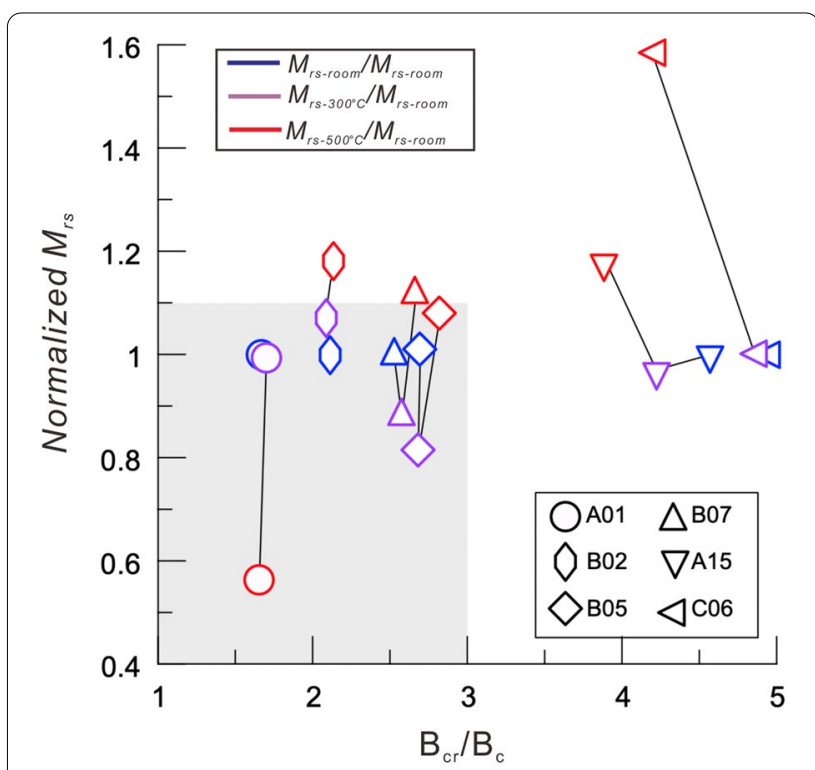

Fig. 7 Plot of the coercivity ratio versus the variation ratio of normalized saturation remanence at room temperature $\left(M_{\mathrm{rs}-\text { room }}\right)$ for the nine samples that passed the selection criteria

In addition to the thermal alteration effects, PSD/ MD particles can also seriously distort the Arai plot. To simultaneously consider these two effects, we constructed a new correlation between $\mathrm{CI}$ and $B_{\mathrm{cr}} / B_{\mathrm{c}}$ (Fig. 7). Clearly, nearly all samples with higher paleointensity have $B_{\mathrm{cr}} / B_{\mathrm{c}}>3$ and $\mathrm{CI}>10 \%$. This strongly indicates that both of these factors can distort the Arai plot, yielding biased paleointensity values. In contrast, samples with $B_{\mathrm{cr}} / B_{\mathrm{c}}<3$ and $\mathrm{CI}<10 \%$ yield an average paleointensity value of $39.70 \pm 7.56 \mu \mathrm{T}$, which is closer to the expected value (Table 1). This strongly indicates that positive pTRM checks indeed cannot exclude a large amount of failed estimations, likely because of the mechanism proposed by Qin et al. (2011) and Zhao et al. (2014).

Our study provides practical new criteria to determine the fidelity of the paleointensity, especially for results with conventional positive checks. This raises a serious question for existing paleointensity results from the geological record. We strongly suggest that the domain state and thermal stability of samples be systematically incorporated into the paleointensity studies, except for all conventional criteria.

\section{Conclusions}

We presented the paleointensities of 1960 Kilauea lava flow samples using the temperature dependence of the hysteresis parameters according to modified Thellier experiments using the IZZI protocol. Only 6 out of 30 samples succeeded according to the positive pTRM checks. However, a large proportion of the "successful" paleointensity results 
failed to predict the expected value. This strongly indicates that positive pTRM checks cannot completely exclude failed results because conventional pTRM checks cannot detect thermal alterations when the unblocking temperature of the newly formed magnetic particles is higher than the treatment temperature. Therefore, we propose that a combination of the chemical index and the domain state parameters be used in future studies, especially for older samples, to improve the fidelity of the paleointensity results.

\begin{abstract}
Abbreviations
AF: Alternating-field; ARM: Anhysteretic remanent magnetization; ChRM: Characteristic remanent magnetization; DRM: Depositional remanent magnetization; IRM: Isothermal remanent magnetization; IGRF: International Geomagnetic Reference Field; IZZI-T method: Thellier method with the IZZI protocol for absolute paleointensity determination; MAD: Maximum angular deviation; MD: Multi-domain; $M_{\mathrm{s}}$ : Saturation magnetization; $M_{\mathrm{rs}}$ : Saturation remanence; $B_{c}$ : Magnetic coercivity; $B_{c:}$ : Coercivity of remanence; PTRM: Partial thermal remanent magnetization; PSD: Pseudo-single-domain; RPI: Relative paleointensity determination; SD: Single-domain; $T_{\mathrm{ub}}$ : Unblocking temperature; $T_{\mathrm{b}}$ : Blocking temperature; TCRM: Thermochemical remanent magnetization; TRM: Thermoremanent magnetization; VFTB: Variable field translation balance.
\end{abstract}

\section{Acknowledgements}

We thank Profs. Lisa Tauxe, Huapei Wang, and Greig Paterson for constructive comments to greatly improve the quality of the manuscript.

\section{Authors' contributions}

DJ: writing and editing; QL: conceptualization, writing and editing, funding acquisition; YY: methodology, software; YY: reviewing and editing; XZ: software; HQ: methodology. All authors read and approved the final manuscript.

\section{Funding}

This study was supported by the National Science Foundation of China (41874078), and the Shenzhen Science and Technology Program (KQTD20170810111725321). This work was also supported by the institute for Korea Spent Nuclear Fuel (iKSNF) and National Research Foundation of Korea (NRF) grant funded by the Korea government (Ministry of Science and ICT, MSIT) (no. 2021M3E1A1085200).

\section{Availability of data and materials}

Data are available on request by contacting QSL.

\section{Declarations}

\section{Competing interests}

The authors declare that they have no competing interests.

\section{Author details}

${ }^{1}$ Centre for Marine Magnetism (CM2), Department of Ocean Science and Engineering, Southern University of Science and Technology, Shenzhen 518055, China. ${ }^{2}$ Southern Marine Science and Engineering Guangdong Laboratory (Guangzhou), Guangzhou, China. ${ }^{3}$ Center for Advanced Marine Core Research, Kochi University, Nankoku 783-8502, Japan. ${ }^{4}$ Department of Geological Sciences, Chungnam National University, 34134 Daejeon, South Korea. ${ }^{5}$ Research School of Earth Sciences, Australian National University, Canberra, ACT, Australia. ${ }^{6}$ Palaeomagnetism and Geochronology Laboratory, State Key Laboratory of Lithospheric Evolution, Institute of Geology and Geophysics, Chinese Academy of Sciences, 100029 Beijing, China.

\section{References}

Abokodair AA (1977) The accuracy of the Thellier's technique for the determination of paleointensities of the Earth's magnetic field. PhD thesis, University of California, Santa Cruz.

Aitken MJ, Allsop AL, Bussell GD, Winter MB (1988) Determination of the intensity of the Earth's magnetic field during archaeological times: reliability of the Thellier Technique. Rev Geophys 26(1):3-12. https://doi.org/10.1029/ RG026i001 p00003

Biggin AJ (2010) Are systematic differences between thermal and microwave Thellier-type palaeointensity estimates a consequence of multidomain bias in the thermal results? Phys Earth Planet Inter 180(1-2):16-40. https://doi.org/10.1016/j.pepi.2010.07.008

Biggin AJ, Piispa EJ, Pesonen LJ, Holme R, Paterson GA, Veikkolainen T, Tauxe L (2015) Paleomagnetic field intensity variations suggest mesoproterozoic inner-core nucleation. Nature 526:245-248. https://doi.org/10.1038/natur e15523

Böhnel H, Herrero-Bervera E, Dekkers M (2011) Paleointensities of the Hawaii 1955 and 1960 lava Flows further validation of the multi-specimen method. In: Petrovsky E, Herrero-Bervera E, Harinarayana T, Ivers D. Eds. Earth's Magnetic Interior. Vol. 1. 195-211.

Calvo M, Prévot M, Perrin M, Riisager I (2002) Investigating the reasons for the failure of palaeointensity experiments: a study on historical lava flows from Mt. Etna (Italy). Geophys J Int 149(1):44-63. https://doi.org/10. 1046/j.1365-246X.2002.01619.x

Calvo-Rathert M, Morales-Contreras J, Carrancho Á, Goguitchaichvili A (2016) A comparison of Thellier-type and multispecimen paleointensity determinations on Pleistocene and historical lava flows from Lanzatore (Canary Islands, Spain). Geochem Geophys Geosyst 17:3638-3654. https://doi. org/10.1002/2016GC006396

Channell JET, Xuan C, Hodell DA (2009) Stacking paleointensity and oxygen isotope data for the last 1.5 Myr (PISO-1500). Earth Planet Sci Lett 283(1-4):14-23. https://doi.org/10.1016/j.epsl.2009.03.012

Chauvin A, Roperch P, Levi S (2005) Reliability of geomagnetic paleointensity data: the effects of the NRM fraction and concave-up behavior on paleointensity determinations by the Thellier method. Phys Earth Planet Inter 150(4):265-286. https://doi.org/10.1016/j.pepi.2004.11.008

Coe RS (1967) Paleo-intensities of the earth's magnetic field determined from tertiary and quaternary rocks. J Geophys Res 72(12):3247-3262. https:// doi.org/10.1029/JZ072i012p03247

Coe RS, Grommé CS, Menkinen EA (1978) Geomagnetic paleointensities from radiocarbon-dated lava flows on Hawaii and the question of the Pacific nondipole low. J Geophys Res 83(B4):1740-1756. https://doi.org/10.1029/ JB083iB04p01740

Coe RS, Riisager J, Plenier G, Leonhardt E, Krash D (2004) Multidomain behavior during Thellier paleointensity experiments: result from the 1915 Mt. Lassen flow. Phys Earth Planet Interiors. 147(2-3):141-153. https://doi.org/10. 1016/j.pepi.2004.01.010

Cromwell G, Tauxe L, Staudigel H, Ron H (2015) Paleointensity estimates from historic and modern Hawaiian lava flows using glassy basalt as a primary source material. Phys Earth Planet Interiors. 241:44-56. https://doi.org/10. 1016/j.pepi.2014.12.007

Day R, Fuller M, Schmidt VA (1977) Hysteresis properties of titanomagnetites: grain-size and compositional dependence. Phys Earth Planet Interiors. 13(4):260-267. https://doi.org/10.1016/0031-9201(77)90108-X

de Groot LV, Béguin A, Kosters ME, van Rijsingen EM, Struijk ELM, Biggin AJ, Hurst EA, Langereis CG, Dekkers MJ (2015) High paleointensities for the Canary Island constrain the Levant geomagnetic high. Earth Planet Sci Lett 419:154-167. https://doi.org/10.1016/j.epsl.2015.03.020

Dunlop DJ (2002) Theory and application of the Day plot (Mrs/Ms versus Hcr/ Hc) 2. Application to data ricks, sediments, and soils. J Geophys Res. https://doi.org/10.1029/2001JB000486

Dunlop DJ, Ozdemir O (2001) Beyond Neel's theories: thermal demagnetization of narrow-band partial thermoremanent magnetizations. Phys Earth Planet Interior 126(1-2):43-57. https://doi.org/10.1016/S0031-9201(01) 00243-6 
Fabian K (2009) Thermochemical remanence acquisition in single-domain particle ensembles: a case for possible overestimation of the geomagnetic paleointensity. Geochem Geophys Geosyst 10(6):Q06Z03. https:// doi.org/10.1029/2009GC002420

Frey FA, Wise WS, Garcia MO, West H, Kwon S-T, Kennedy A (1990) Evolution of Mauna Kea Volcano, Hawaii: Petrologic and geochemical constraints on postshield volcanism. J Geophy Res. 95(B2):1271-1300. https://doi. org/10.1029/JB095iB02p01271

Grappone JM, Biggin AJ (2019) Solving the mystery of the 1960 Hawaiian lava flow implications for estimating Earth's magnetic field. Geophys J Int 218(3):1796-1806. https://doi.org/10.1093/gji/ggz252

Haag M, Dunn J, Fuller M (1995) A new quality check for absolute palaeointensities of the Earth magnetic field. Geophys Res Lett 22(24):35493552. https://doi.org/10.1029/95GL03333

Henry B, Jordanova D, Jordanova N, Goff ML (2005) Transformations of magnetic mineralogy in rocks revealed by difference of hysteresis loops measured after stepwise heating: theory and case studies. Geophys J Int 162(1):64-78. https://doi.org/10.1111/j.1365-246X.2005.02644.x

Herrero-Bervera E, Valet J-P J-P (2009) Testing determinations of absolute paleointensity from the 1995 and 1960 Hawaiian flows. Earth Planet Sci Lett 287(3-4):420-433. https://doi.org/10.1016/j.epsl.2009.08.035

Hill MJ, Shaw J (2000) Magnetic field intensity study of the 1960 Kilauea lava flow, Hawaii, using the microwave paleointensity technique. Geophys J Int 142(2):487-504. https://doi.org/10.1046/j.1365-246x.2000.00164

Kirschvink J (1980) The least-squares line and plane and the analysis of paleomagnetic data. Geophys J Int 62(3):699-718. https://doi.org/10. 1111/j.1365-246X.1980.tb02601.x

Larson RL, Olson P (1991) Mantle plumes control magnetic reversal frequency. Earth Planet Sci Lett 107(3-4):437-447. https://doi.org/10. 1016/0012-821X(91)90091-U

Macouin M, Valet J-P, Besse J (2004) Long-term, evolution of the geomagnetic dipole moment. Phys Earth Planet Interiors. 147(2-3):239-246. https://doi.org/10.1016/j.pepi.2004.07.003

Morales J, Zhao X, Goguitchaichvili A (2010) Geomagnetic field intensity from Kilauea 1995 and 1960 lava flows: towards a better understanding of paleointensity. Stud Geophys Geod 54:561-574. https://doi.org/10. 1007/s11200-010-0034-6

Nagata T, Arai Y, Momose K (1963) Secular variation of the geomagnetic total force during the last 5000 years. J Geophys Res 68:5277-5281. https://doi.org/10.1029/j.2156-2202.1963.tb00005.x

Oishi Y, Tsunakawa H, Mochizuki N, Yamamoto Y, Wakabayashi K-I, Shibuya $H$ (2005) Validity of the LTD-DHT Shaw and Thellier palaeointensity methods: a case study of the Kilauea 1970 lava. Phys Earth Planet Inter 149(3-4):243-257. https://doi.org/10.1016/j.pepi.2004.10.009

Olson P, Deguen R, Hinnov LA, Zhong S (2013) Controls on geomagnetic reversals and core evolution by mantle convection in the Phanerozoic. Phys Earth Planet Interiors. 214:87-103. https://doi.org/10.1016/j.pepi. 2012.10.003

Paterson GA, Biggin AJ, Hodgson E, Hill MJ (2015) Thellier-type paleointensity data from multidomain specimens. Phys Earth Planet Interiors 245:117-133. https://doi.org/10.1016/j.pepi.2015.06.003

Qin H, He H, Liu QS, Cai S (2011) Paleointensity just at the onset of the Cretaceous normal superchron. Phys Earth Planet Interiors. 187(3-4):199211. https://doi.org/10.1016/j.pepi.2011.05.009

Riisager P, Riisager J (2001) Detecting multidomain magnetic grains in Thellier palaeointensity experiments. Phys Earth Planet Inter 125(14):111-117. https://doi.org/10.1016/S0031-9201(01)00236-9

Riisager J, Perrin M, Riisager P, Ruffet G (2000) Paleomagnetism, paleointensity and geochronology of Miocene basalts and baked sediments from Velay Oriental, French Massif Central. J Geophys Res Solid Earth 105(B1):883-896. https://doi.org/10.1029/1999JB900337

Ritcher DH, Eaton JP, Murata KJ, Ault WU, Krivoy HL (1970) Chronological narrative of the 1959-60 eruption of Kilauea Volcano, Hawaii. USGS survey professional Paper, 537-E. https://doi.org/10.3133/pp537E.
Rowland SK, George WPL (1987) Toothpaste lava: Characteristic and origin of a lava structural type transitional between pahoehoe and aa. Bull Volcanol 49:631-641. https://doi.org/10.1007/BF01079968

Smirno A, Tarduno JA (2003) Magnetic hysteresis monitoring of Cretaceous submarine basaltic glass during Thellier paleointensity experiments: evidence for alteration and attendant low field bias. Earth Planet Sci Lett 206(3-4):571-585. https://doi.org/10.1016/S0012-821X(02)01123-8

Tanaka H, Kono M (1991) Preliminary results and reliability of paleointensity studies on historical and ${ }^{14} \mathrm{C}$ dated Hawaiian Lavas. J Geomagn Geoelectr 43:375-388. https://doi.org/10.5636/jgg.43.375

Tanaka H, Athanassopoulos JDE, Dunn JR, Fuller M (1995) Paleointensity determinations with measurements at high temperature. J Geomagn Geoelectr 47(1):103-113. https://doi.org/10.5636/jgg.47.103

Tarduno JA, Cottrell RD, Watkeys MK, Bauch D (2007) Geomagnetic field strength 3.2 billion years ago recorded by single silicate crystals. Nature 446:657-660. https://doi.org/10.1038/nature05667

Tauxe $L$ (1993) Sedimentary records of relative paleointensity of the geomagnetic field: theory and practice. Rev Geophys 31(3):319-354. https://doi.org/10.1029/93RG01771

Tauxe L, Staudigel H (2004) Strength of the geomagnetic field in the Cretaceous Normal Superchron: new data from submarine basaltic glass of the Troodos Ophiolite. Geochem Geophys Geosyst 5:Q02H06. https:// doi.org/10.1029/2003GC000635

Thebault E, Finlay C, Beggan C, Alken P, Aubert J, Barrois O, Bertrand F, Bondar T, Boness A, Brocco L, Canet E, Chambodut A, Chulliat A, Coisson P, Civet F, Du A, Fournier A, Fratter I, Gillet N, Hamilton B, Hamoudi M, Hulot G, Jager T, Korte M, Kuang W, Lalanne X, Langlais B, Leger J, Lesur V, Lowes F, Macmillan S, Mandea M, Manoj C, Maus S, Olsen N, Petrov V, Ridley V, Rother M, Sabaka T, Saturnino D, Schachtschneider R, Sirol O, Tangborn A, Thomson A, Toffner-Clausen L, Vigneron P, Wardinski I, Zvereva T (2015) International geomagnetic reference field: the 12th generation. Earth Planets Space. https://doi.org/10.1186/ s40623-015-0228-9

Thellier E (1938) Sur l'aminatation des teres cuites et ses applications g'eophysique. Annales De l'institute Physique Dy Globe, Paris 16:157-302

Thellier E, Thellier O (1959) Sur l'intensité de champ magnétique terrestre dans le passé historique et géologique. Annales De Géophysique 15:285-378

Tsunakawa H, Shaw J (1994) The Shaw method of paleointensity determinations and its application to recent volcanic rocks. Geophys J Int 118(3):781-787. https://doi.org/10.1111/j.1365-246x.1994.tb03999.x

Valet J-P (2003) Time variations in geomagnetic intensity. Rev Geophy 41(1):1004. https://doi.org/10.1029/2001RG000104

Valet J-P, Herrero-Bervera E (2000) Paleointensity experiments using alternating field demagnetization. Earth Planet Sci Lett 177(1-2):43-88. https://doi.org/10.1016/S0012-821X(00)00036-4

Valet J-P, Meynadier L, Guyodo Y (2005) Geomagnetic dipole strength and reversal rate over the past two million years. Nature 435:802-805. https://doi.org/10.1038/nature03674

Wang HP, Kent DV (2013) A paleointensity technique for multidomain igneous rocks. Geochem Geophys Geosyst 14(10):4195-4213. https://doi. org/10.1002/ggge.20248

Wang H, Kent DV (2021) RESET: A method to monitor thermoremanent alteration in Thellier-series paleointensity experiments. Geophys Res Lett 48:e2020GL091617. https://doi.org/10.1029/2020GL091617

Yamamoto Y, Tsunakawa H, Shibuya H (2003) Paleointensity study of the Hawaiian 1960 lava: implications for possible causes of erroneously high intensities. Geophys J Int 153(1):263-276. https://doi.org/10. 1046/j.1365-246X.2003.01909.x

Yamazaki T, Oda H (2005) A geomagnetic paleointensity stack between 0.9 and 3.0 Ma from equatorial Pacific sediment cores. Geochem Geophys Geosyst 6(11):Q11H 20. https://doi.org/10.1029/2005GC001001 
York D (1969) Least squares fitting of a straight line with correlated errors. Earth Planet Sci Lett 5:320-324. https://doi.org/10.1016/S0012-821(68) 80059-7

Yu Y (2012) High-fidelity paleointensity determination from historic volcanoes in Japan. J Geophys Res Solid Earth 117(B8):B08101. https://doi. org/10.1029/2012JB009368

Yu Y, Dunlop DJ (2003) On partial thermoremanent magnetization tail checks in Thellier paleointensity determination. J Geophys Res Solid Earth 108(B11):2523. https://doi.org/10.1029/2003JB002420

Yu Y, Tauxe L, Genevey A (2004) Toward an optimal geomagnetic field intensity determination technique. Geochem Geophys Geosyst 5(2):Q2H07. https://doi.org/10.1029/2003GC000630

Zhao XY, Liu QS, Paterson GA, Qin HF, Cai SH, Yu Y, Zhu RX (2014) The effects of secondary mineral formation on Coe-type paleointensity determinations: Theory and simulation. Geochem Geophys Geosyst 125(4):1215-1234. https://doi.org/10.1002/2013GC005165

Ziegler LB, Constable CG, Johnson CL, Tauxe L (2011) PADM2M: a penalized maximum likelihood model of the 0-2 Ma paleomagnetic axial dipole moment. Geophys J Int 184(3):1069-1089. https://doi.org/10.1111/j. 1365-46X.2010.04905.x

\section{Publisher's Note}

Springer Nature remains neutral with regard to jurisdictional claims in published maps and institutional affiliations.

\section{Submit your manuscript to a SpringerOpen ${ }^{\circ}$ journal and benefit from:}

- Convenient online submission

- Rigorous peer review

- Open access: articles freely available online

- High visibility within the field

- Retaining the copyright to your article

Submit your next manuscript at $\boldsymbol{\nabla}$ springeropen.com 